\title{
Essential phospholipids protection against mercury uptake and histopathological changes in the intestine of fish, Oreochromis mossambicus (Trewavas)
}

\author{
Suresh Kothari* and Neha Choughule \\ School of Studies in Zoology and Biotechnology,Vikram University, Ujjain - 456010, INDIA \\ *Corresponding author. E-mail: Sckothari 2004@yahoo.com
}

\begin{abstract}
Histochemical examination of fingerlings and adults of freshwater teleost Oreochromis mossambicus (Trewavas) exposed to sublethal concentration of $\mathrm{HgCl}_{2}(0.15 \mathrm{mg} / \mathrm{l})$ for 30 days revealed considerable uptake of mercury by their respective intestines. Simultaneous co-administration of Essential phospholipids (EPL) along with food to the fishes, significantly supressed mercury uptake by the intestinal tissues, except the goblet cells which were still loaded with $\mathrm{Hg}$ in both stages. Due to accumulated mercury visible histopathological damage was seen in muscle layers, lamina propria and basement membrane of columnar cells. No noticeable damage in intestine was seen, when EPL was simultaneously fed to fishes along with $\mathrm{HgCl}_{2}$ exposure. Results suggest that EPL plays prophylactic role against metal uptake and structural damage in fish intestine exposed to inorganic mercury.
\end{abstract}

Keywords : Mercuric chloride, Intestine, Essential phospholipids

\section{INTRODUCTION}

Mercury is recognised as a highly toxic metal and has no known beneficial effect on animals and its accumulation in the animal bodies causes serious health hazards. Bioaccumulation of mercury is reported in several freshwater species (Kennedy, 2003 and Storelli et al., 2007). Mercury is known to cause severe histopathological effects in fish intestine (Banerjee and Bhattacharya, 1995 and Kothari et al., 1999). Beneficial role of essential phospholipids against mercury (Kothari, 2008), Zinc (Kothari and Soni, 2002, 2004) and cadmium (Kothari etal., 1999 and Kothari et al., 2005) in fish organs is on record.

The present study has been undertaken to find out protective action of Essential phospholipids against metal uptake and histological changes caused due to mercury exposure in freshwater finfish $\mathrm{O}$ reochromis mossambicus (Trewavas).

\section{MATERIALS AND METHODS}

Fingerling and adult stages of freshwater fish Oreochromis mossambicus were procured from local Govt. fish farm. Average length and weight of fingerlings and adults were $3 \mathrm{~cm}$ and $1 \mathrm{~g}$ and $11 \mathrm{~cm}$ and $25 \mathrm{~g}$, respectively. Both stages of fish were acclimatized to laboratory conditions for 14 days in stored tap water. Fish were treated with $0.1 \% \mathrm{KMno}_{4}$ solution to remove any dermal infection. Analytical grade mercuric chloride was used as a toxicant for this study. $\mathrm{LC}_{50}$ value and experimental concentration of mercuric chloride were 0.15 $\mathrm{mg} / \mathrm{l}(96 \mathrm{~h})$ and $0.15 \mathrm{mg} / \mathrm{l}$, respectively.
Source of Essential phospholipids (EPL) for this study was the drug 'Essentiale' manufactured by Nattermann, Germany. Each $175 \mathrm{mg}$ Essentiale capsule contained: Phosphatidylcholine (80\%), lyso - Phosphatidylcholine (30\%), Phosphatidylethanolamine (5\%) and Other lipids (12\%).

EPL was given at the rate of $15 \mathrm{mg} / \mathrm{kg}$ body weight of the fish. Fingerlings and adults were fed daily at the rate of $10 \mathrm{mg}$ and $25 \mathrm{mg}$ per aquarium (25 fish), respectively. Food was given in the form of food balls prepared by adding few drops of liquid paraffin. In EPL treated group food was mixed with EPL and liquid paraffin.

Physico - Chemical parameters of stored tap water were D.O. - $6.4 \mathrm{mg} / \mathrm{l}$, hardness - $180 \mathrm{mg} / \mathrm{l}$, total alkalinity - 152 $\mathrm{mg} / \mathrm{l}$, chloride $-98.99 \mathrm{mg} / \mathrm{l}, \mathrm{pH}-7.2$ and water temperature ranged between $25-27^{\circ} \mathrm{C}$.

Three groups each of 25 fingerlings and adults were maintained in glass aquaria, each containing 501 water. Group I : Served as control (without poison) and animals were fed on plain food, Group II : Animals were exposed to $0.15 \mathrm{mg} / 1 \mathrm{HgCl}_{2}$ and were fed on plain food, Group III : Animals were exposed to $0.15 \mathrm{mg} / 1 \mathrm{HgCl}_{2}$ and were simultaneously fed on food containing EPL.

Aquaria water was changed on every fourth day. Mercury solution was added afresh in II and III groups, after renewal of water. Food and drug were given daily. Duration of experiment was 30 days. Young and adult fish were dissected on $31^{\text {st }}$ day and intestine was removed and cleared off and processed for various studies as under.

Histochemical demonstration of mercury in paraffin 
sections was made using sulphide silver method (after Timm, 1958) as described by Pearse (1972). Mercury salt was deposited in liver tissues as brownish black deposits. The routine paraffin sections of 5 micron thickness were cut and double stained with haematoxylin and eosin.

\section{RESULTS}

Histochemical localisation of mercury : Tissue distribution of mercury has been shown histochemically in intestine of both stages of fish. Metal salt precipitated as sulphide was seen as brownish - black deposit in tissue sections. Intestine of control (Group I) fingerling (Fig.1) and adult fish reacted negatively to sulphide - silver staining, indicating complete absence of mercury. Pattern of mercury distribution in both stages of fish exposed to $\mathrm{HgCl}_{2}$ (Group II) was found to be similar. Mercury was localised in muscle layers, submucosa, lamina propria, columnar epithelium and goblet cells in fingerling (Fig.2). In adult, mercury in gut wall was randomly distributed (Fig.3) as against fingerling, where it was uniformly distributed. Concomittant administration of essential phospholipids significantly supressed mercury uptake by both stages of the fish. However, in EPL treated fish mercury was selectively localised in serosa and goblet cells in both stages of the fish (Fig.4). Rest of the component tissues of intestine were devoid of mercury, except some scattered granules of mercury in submucosal tissue.

Histopathology : Structural deformities induced by toxic action of $\mathrm{HgCl}_{2}$ and protective action of EPL was studied histologically in fingerling and adult finfish. Histologically, intestine of both stages is similar and is consisted of mucosa, sub-mucosa, muscularis and outer layer of serosa. Columnar epithelial cells are lined with a thin top plate having basal nuclei (Fig.5). Intestine of adult fish has more number of villi and mucous secreting cells as against fingerling stage. In fingerling mucous secreting goblet cells are fewer in number. In fingerling intestine mercury caused disorganisation and degeneration of muscle fiberes and contraction of submucosal tissue. Tissue free gaps were observed in the musculature and lamina propria. Degenerative changes of various degree were noticed in the mucosa. Due to degeneration of basement membrane columnar nuclei in some cases were liberated in the submucosal zone. Top plate was also found damaged at places (Fig. 6). Shrinkage in the musculature and lamina propria and degeneration of submucosal tissue and basement membrane were among the major pathological symptoms induced due to mercury toxicity in the intestine of adult fish. At places vacuolization in mucosa was also seen (Fig.7). Concomittant administration of EPL along with $\mathrm{Hg}$ exposure maintained almost normal histological architecture of intestine in both stages of the fish (Fig. 8).

\section{DISCUSSION}

In fish, effect of mercury which is a highly toxic, nonessential and non-biodegradable heavy metal has been attempted by several workers (Kirubagaran and Joy, 1988; Sunderland and Chmura, 2000 and Kothari et al., 2003). Very few workers have shown histochemical distribution of mercury in fish organs in the past (Baatrupet al., 1986; Kumar and Kothari, 1990; Bhoraskar and Kothari, 1993; Geed and Kothari, 1994; and Kothari, 2008). Boudou et al., (1991) have shown that in any contamination process irrespective of biological complexity of the organisms; accumulation of toxic product is necessarily based on interaction with biological barriers (gill, intestine etc.) which separate the surrounding environment from the internal medium. At the cellular level the plasmic membrane may be considered primarily as a complex system of potential binding sites of mercury. The cell membrane is known to act as a biological barrier towards metal transfers between the external medium and the cytoplasm (Boudou and Ribeyre, 1983).

Intestine of both stages of $O$. mossambicus was susceptible to mercury and intestinal villi as indicated by its heavy deposits of mercury in it. In fingerling stage, gut wall also contained significant amount of $\mathrm{Hg}$, whereas adult fish gutwall revealed only scattered traces of mercury. Mercury exposure when combined with EPL treatment, indicated significant reduction in mercury uptake, histochemically. In both the stages only mucous secreting goblet cells and serosa revealed mercury accumulation.

Little information is available on the role of lipidic bilayer of biological membrane in the binding of mercury. Inorganic mercury is able to form reversible complexes with some phospholipids in chloroform (Phosphatidylcholine, Phosphatidylserine and phosphatidylethanolamine). It is indicated that EPL response to mercury is variable in liver and intestine of O. mossambicus as there was no mercury uptake by liver in presence of EPL (Kothari, 2008), whereas, noticeable amount of $\mathrm{Hg}$ in goblet cells and serosa of intestine is noticed during the present investigation.

Mercury accumulation in intestine is known to cause structural damage inhibiting nutrient transport (Millar et. al., 1980 and Millar, 1981). In finfish intestine exposed to $\mathrm{HgCl}_{2}$ damage in musculature, submucosa, lamina propria, basement membrane and top plate was evidently seen. These results are consistent with those described by earlier workers in various fish species (Bano and Hasan 1990; Bhoraskar and Kothari, 1993; Bhalerao, 1996; and Gupta and Jain, 2007). The severity of damage was greater in adult than in the young fish.

Simultaneous treatment of mercury exposed fish with EPL revealed almost normal histological architecture in both stages of fish. However, in case of adult fish fed with 


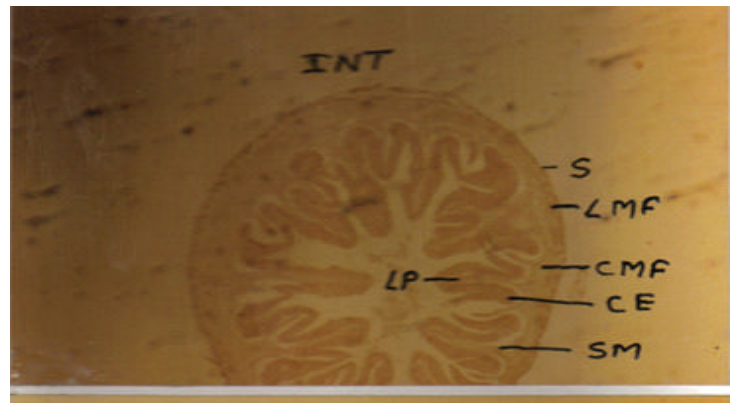

1

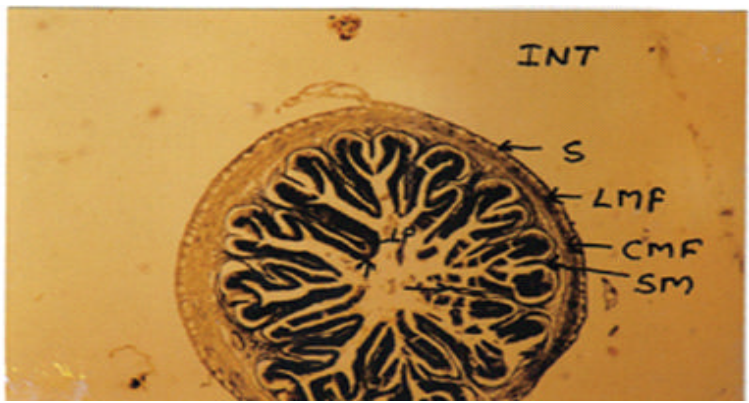

3
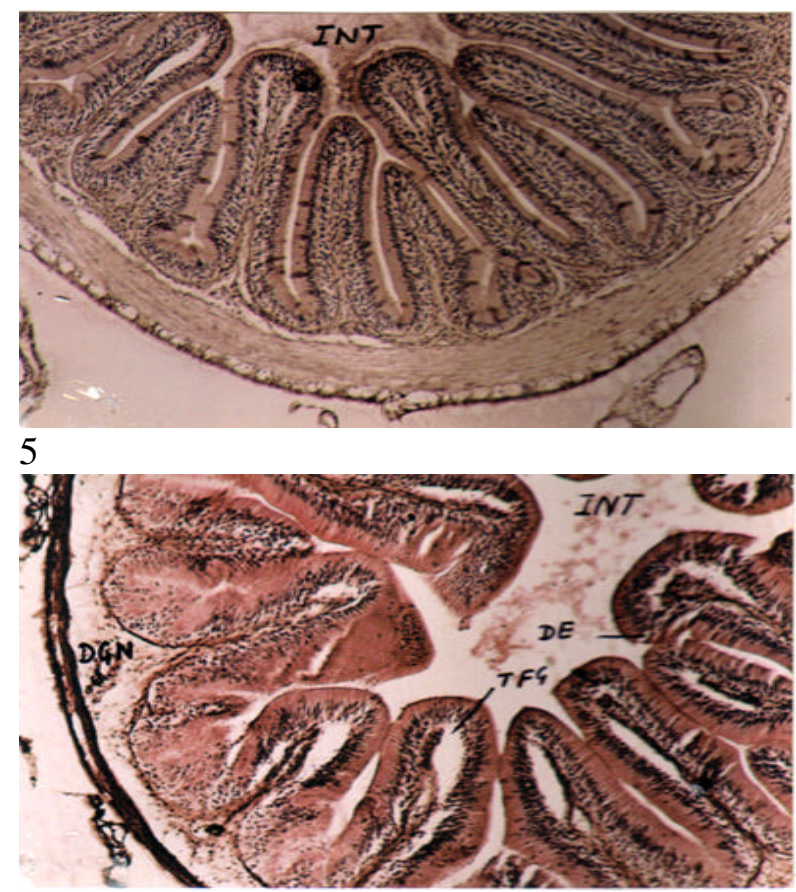

7

Figs. 1 - 8. 1. Section of intestine of control fingerling showing negative reaction for sulphide staining. Note the complete absence of mercury, 2. Section of mercury exposed intestine of young fish showing heavy deposition of mercury in gut wall, columnar epithelium, submucosa and lamina propria,3. Section of intestine of $\mathrm{HgCl}_{2}$ treated adult intestine showing heavy deposition in the villi with weak traces in musculature, 4. Section of intestine of fingerling treated with EPL showing marked reduction in mercury accumulation. Mercury is mainly locaized in serosa \& goblet cells, 5. T.S. of intestine of control adult fish revealing normal histology, 6. T.S. of intestine of mercury treated fingerling showing degeneration of submucosa, shrinkage of lamina propria and damaged to columnar epithelium, 7. T.S. of intestine of $\mathrm{HgCl}_{2}$ treated adult fish showing damage to submucosa, lamina propria and columnar, epithelium,8. T.S. of intestine of EPL treated adult fish exhibiting almost normal histology. Abbreaviations : - CE Columnar epithelium; $\boldsymbol{C M F}$ - Circular Muscle Fibers; DE -Damaged epithelium; GE - Goblet cells; INT - Intestine; LMF longitudinal muscle fibers; LP - Lamina propria; $\boldsymbol{M D}$ - Mercury deposition; SLP - Shruken lamina propria; SM - Submucosa; TFG - Tissue free gap.) 
EPL; vacoulization in intestinal villi was still persistent. It is suggested that exogenous supply of EPL substances has a protective action against mercury induced pathological changes and consequently helps the fish in maintaining normal intestinal function.

Mercury toxicity has been related to lipid peroxidation (Rana et al., 1995 and Elia et al., 2003). It is a chemical process that results in the oxidative deterioration of polyunsaturated fattyacids leading to destructive changes in the lipid of cell membrane (Jobling, 1995). According to Kuntz (1990) protective action of EPL against hepatic disorders seems to be based among others, on the inhibition of lipid peroxidation. Thus, it is presumed that EPL pretreatment afforded protection against mercury toxicity in fish intestine by inhibiting peroxide formation. The effect of EPL in hepatocytes has also been reported to be based in its ability to become incorporated into both normal and damage membrane structures (Maros et al., 1973; and Wallnofer and Hansch, 1973).

Protective action of Essential phospholipids against mercury uptake and histopathological damage in $O$. mossambicus intestine seems to be slightly less than those observed in liver (Kothari, 2008) and gills where no mercury uptake and structural damage was noticed, when simultaneous treatment of EPL was given to experimental fish along with $\mathrm{HgCl}_{2}$ exposure.

\section{REFERENCES}

Baatrup, Erik mogens, Nielsen, G. and Danscher, G. (1986). Histochemical demonstration of two mercury pools in trout tissues; mercury in kidney and liver after Mercuric chloride exposure, Ecotoxicol. Environ. Saf., 12 (3) : 267-282.

Banerjee, S. and Bhatacharya, S. (1995). Histopathological changes induced by chronic nonlethal levels of the elsan, mercury and ammonia in the small intestine of Channa punctatus (Bloch). Ecotoxicol Environ. Saf.,31(1): 62-80.

Bano, Y. and Hasan, M. (1990). Histopathological lesions in the body organs of a Catish H.fossilis following $\mathrm{Hg}$ intoxication. J. Environ. Sc. Health B., 25 (1) : 67-85.

Bhalerao, S. (1996). Liv.52 Protection against $\mathrm{HgCl}_{2}$ toxicity in target organs of a Catfish H. Fossilis (BL.). A Histological and biochemical study. Ph.D. Thesis, Vikram University, Ujjain (M.P.).

Bhoraskar, J. and Kothari, S. (1993). Toxicity of mercury and zinc in the liver of a Catfish Clarias batrachus (Linn). In : K. S. Rao (Ed.), Recent Advances In fresh water biology. pp: 285-298. New Delhi ( India) Anmol publication.

Boudou, A. and Ribeyre, F. (1983). Contamination of a aquatic biocenoses by mercury compounds an experimental ecotoxicological approach In: J.O. Nraigu (Ed.) pp: 117136. J. Wily, New York, Aquatic Toxicology.

Boudou, A., Delnomdedieu, M., Georges, D., Ribeyre, F. and Sqouter, E. (1991). Fundamental roles of biological barriers in mercury accumulation and transfer in fresh water ecosystem. Water, Air and Soil Pollution, 56: 807-821.

Elia, A.C., Galarini, R., Taticchi, M. I., Darr, A .J. M. and
Mantilacci, L. (2003). Antitoxidant responses and bioaccumulation in Ictalurus melas under mercury exposure. Ecotoxicol. Environ. Saf., 55.(2): 162-167.

Geed, S. and Kothari, S. (1994). Role of an indigenous drug Liv. 52 against mercuric chloride toxicity in the liver of a freshwater teleost. Heteropneustertes fossilis ( B1): A Histochemical and Histological study. Indian. J. Environ. Toxicol., 4 (2) 39-43.

Gupta, R. K. and Jain, K .L. (2007). Histopatholgical Analysis of impact of mercury and cobalt in a Telecost, Cirrhinus mrigala. NSH. Proceed of DAE-BRNS National Syposiumn Limnology ( NSL-07) Udaipur:373-375.

Jobling, M. (1995). Environmental biology of fishes. London. Champman \& Hall.

Keneedy, C .I.( 2003). Uptake and accumulation of mercury from dental amalgam in the cannon goldfish Carassius auratus. Environ. Pollut., 21(3): 321-326.

Kirubagaran, R. and Joy, K. P. (1988). Toxic effects of three mercurial compound on survival and histology of the kidney of the Catfish Calarias batrachus (L.) Ecotoixcol Environ. Safety.,15:171-179.

Kothari, S. (2008). Protective action of essential phospholipids accumulation and toxicity of mercuric chloride in fish liver, In: Status of medical biotechnology research in the state of Madhya Pradesh. Past Accomplishments. Current trends and challenges Ahead, P.K. Mishra and K.K. Maudar (Eds.) Bhopal, India MEDBIO-2008. 216-230.

Kothari, S. and Soni, R. (2002). Effect of polyunsaturated fatty acids on zinc induced disturbance in Heteropneustes fossilis intestine. Indian J. Environ. Toxicol., 2(1) 40-42.

Kothari, S. and Soni, R. (2004). Role of polyunsaturated fatty acids againt zinc sulphate toxicity in the gills of a catfish $\mathrm{H}$. Fossilis (Bloch). Journal of Tissue Research, 4 (2): 253256.

Kothari, S., Bhalerao, S. and Jat, D. (2003). Protection by herbal compound against toxic effects of mercuric chloride in fish intestine. J.Ecophysiol. Occup. Health, 3 : 51-58.

Kothari, S. Bhalerao, S. and Sharma, S. K. (1999 a). Effect of a herbal compound on mercury induced biochemical changes in the liver of Catfish, Indian J. Environ. and Toxicol., 9(1) : 30-32

Kothari, S., Pandey, C. and Mahajan, P. (1999b). Role of a drug 'Essentiale' against cadmium toxicity in the intestine of O Mosssambicus (Trewavas). The Fourth Indian Fisheries Forum Proceedings, 24-28: 135-137.

Kothari, S., Trivedi, A., Jat, D. and Sakade, B. (2005). Preventive action of essential phospholiphids against cadmium induced haematological changes in Hetropneustes fossilis (Bloch). Indian J. Environ. Toxicol., 15(1):6-9.

Kumar, R. M. and Kothari, S. (1990). Histological and histochemical studies in the liver of Hetropneustes fossilis(Bloch) treated with mercuric chloride. Environmental Pollution and Health Hazards, Environmental Series, 3 pp: 127-132.

Kuntz, E. (1990). "Essential" phospholipids essential to the liver. Asian Medical News 12(7) 13-14.

Maros, T., Seresturum, L., Lakatos, O., Magda, T., Seresturum, and Blazsek, V. (1973). Investigations regarding the possibility of resorption of the hepatic collagen in experimental toixc cirrhosis, under the effect of "Essential" 
phospholipids. Arzneim Forsch (Drug Res.), 23 (11): 15381542.

Millar, D.S. (1981). $\mathrm{HgCl}_{2}$ inhbition of nutrient transport in teleost fish small instetine. J. Pharmacol . Exp .Ther., 216: 70-76.

Millar, D. S., Shehata, A. T. and Lerner, J. (1980). $\mathrm{HgCl}_{2}$ inhibition of D-glucose transport in Jejunal tissue from 2 days and 21 days chicks. J. Pharmacol exp. Ther., 214: 101105

Pearse, A. G. E. (1972). Histochemistry: Theoritical and Applied $3^{\text {rd }}$ ed, Vol.2 Edinburgh churchill-livingestone.

Rana, S. V. S., Rekha, S. and Seema, V. (1995). Mercury induced lipid peroxidation in kidney, brain and gills of a fresh water fish, Channa punctatus. Japanese Journal of Ichthyology, 42 (3-4): 255-259.
Storelli, M. M., Barone, G., Garofalo, R. and Marcotrigiano, G. O.(2007). Metals and organochlorine compounds in eel. (Anguilla Anguilla)From the Lesina Lagoon, Adriatic Sea (Italy), Food Chemistry, 100:1337-1341.

Sunderland, E. M. and Chmura, G. L. (2000). An inventory of historical mercury emission in Maritime Canada: Implication for present and future contamination. The Sciences of the Total Environment, 256: 39-57.

Wallnofer, H. and Hansch, M. (1973). "Essential" phospholiphids in the treatment of hepatic disease. Medizinischemonatsschrift, 27 (3), 331-336. 